\title{
Corrigendum
}

\section{Inventory management under date-terms supplier trade credit with stochastic demand and leadtime}

DJ Robb ${ }^{1}$ and EA Silver ${ }^{2}$

${ }^{1}$ The University of Auckland, Auckland, New Zealand; and ${ }^{2}$ The University of Calgary, Calgary, Alberta, Canada

Journal of the Operational Research Society (2006) 57, 755. doi:10.1057/palgrave.jors.2602154

Corrections to: Journal of the Operational Research Society (2006) 57, 692-702. doi:10.1057/palgrave.jors.2602042

In Robb and Silver (2006), there are two errors relating to inventory holding costs, namely, (i) in the paragraph covering both columns on page 694, the subscripts of the i's on the fourth and sixth lines should be interchanged, and (ii) in the fifth line of the paragraph immediately following Equation (1) on page 695, the word 'possession' should be replaced with 'capital'.
The authors regret these errors, for which they take full responsibility. They are thankful to Lewis Cao, a postgraduate student at the University of Auckland, for finding the errors.

\section{Reference}

Robb DJ and Silver EA (2006). Inventory Management under dateterms supplier trade credit with stochastic demand and leadtime. J Opl Res Soc 57: 692-702. 